\title{
17. Leadership Practices: Reflections on Australian Political Leadership
}

\section{David Kemp}

\section{Political leadership: the larger story}

This chapter provides some reflections on political leadership in Australia from the perspective of one who has been involved both as an academic studying politics and leadership and as an active participant in national politics for a number of years.

The growing body of literature on political leadership points to many aspects of public leadership that could be (and are) readily illustrated from Australian examples. Paul 't Hart and John Uhr (this volume) usefully bring many of these together in a way that has considerable resonance for one who has been an active practitioner: the close interdependence of leaders and 'followers'; the way in which leaders through their rhetoric present their cases and mobilise support; the significance of the institutional framework within which leadership is offered; and different approaches that may be adopted to political and policy change. Others, of whom Walter and Strangio (2007; see also Walter, this volume) are an example, point to the increasing centralisation of power around prime ministers and wonder how far this is eroding traditional checks and balances within the system of government.

My reaction, as a practitioner, to these useful studies and observations is that there is a need for the larger story to which they contribute to be articulated. As we disaggregate public leadership for analysis we should not lose sight of the larger purposes that have motivated it. There is a macro- as well as a micro-story about political leadership. The larger story has to do with what 't Hart and Uhr call strategic challenges.

The core concern of political leadership is policy. It is by their policy successes and failures that leaders are judged, and on which they ultimately win or lose elections. Voters want leaders to solve problems and policies are the way they do that. It is not just administrative leaders who attempt to 'create public value', to use Mark Moore's term (Moore 1995) and, in the effort to do so, political leaders reorganise government to suit their needs, taking advantage of the opportunities provided by the constitutional arrangements. Whether, in doing so in Australia, they have eroded the checks and balances of the system, or the principal mechanisms of accountability, is an important question but, to understand why the question arises, the larger context of the changing character of Australian political leadership needs to be brought into focus. 
From this perspective, there is a story to be told about Australian political leadership and national policy outcomes over the last four decades. It is a story that transcends political party, though each major party has played a distinctive role in the story, and leaders in each have had to deal with unique internal challenges arising from the distinctive character of their party.

The larger story linking leadership and policy suggests, in turn, a research agenda to do with the relation between a leader and a set of policies: how leaders have approached and dealt with the dominant policy ideas, why they have made the choices they have, why they have organised the advisory process in the way they have, and so forth. Why the agenda transcends party is one of the most interesting questions of all.

I will outline my version of the larger 'macro' story, and then indicate some of the research directions it suggests.

\section{Leadership and public policy}

In recent decades Australia has been through an extraordinary period of policy dynamism that has transformed the national policy framework and Australia's character both as a society and as a component of the global economy. Debates about further national reform dominated the recent election campaign. The journalist Paul Kelly recently suggested (The Australian Literary Review, Oct. 3, 2007) that Australia had been blessed with first class political leaders over this period who, through their leadership, had wrought this transformation and, as a consequence, positioned Australia as an exceptionally successful nation on the global scene.

I believe that, on the whole, this is a valid assessment. To achieve this transformation our political leaders have reorganised the central government of the country; including a radical reinvention of the framework within which the Australian Public Service operates. The reform drive continues to put great pressure for change on the Federal system itself. This reorganisation has occurred to facilitate policy innovation and it has achieved its objective, though it has provoked a debate about the effectiveness of traditional accountability mechanisms.

This is not the place to detail all the components of the policy revolution of the last few decades, but it will be useful to record some of the major elements. Central has been a change in the role of government. Government has largely withdrawn from its role as an active participant in the economy through government owned enterprises (usually monopolies). The economy has been opened to international competition and efforts to protect Australian industry (with few exceptions) have been abandoned. The tax system (principally through the consumption tax) has become much more neutral in its sectoral impact. Domestic regulation to protect major industry sectors from competitive entrants 
has largely disappeared. Market forces have been given a greatly expanded role in initiating innovation and determining enterprise success and failure. There has been a significant devolution of the management of workplace relations to the enterprise level. The movement away from the politically managed economy was symbolised by the floating of the Australian dollar and financial deregulation. Monetary policy has been handed to an independent Reserve Bank, and Keynesian efforts at demand management have largely been set aside.

Policy innovation has reached deeply into many areas of social policy. Consumer choice has been given an expanded role in social areas such as employment services, education, and health, and market mechanisms are increasingly being used to manage formerly public environmental goods such as water (and greenhouse gases). Private funding and investment in areas formerly regarded as public goods (education, training, health, roads and infrastructure) has greatly expanded. The welfare system has moved from one based simply on payment of benefits to one based on training and incentives to participate through principles of 'mutual obligation'. The overturning of the decades old framework for aboriginal policy in the Northern Territory is but the latest example. Perhaps most fundamentally, in family and gender relations, government has withdrawn from the attempt to define distinct roles for men and women by law and has attempted to outlaw employment and other discrimination based on gender, race or religion.

In seeking a comparative perspective 't Hart and Uhr (this volume) pose the question: is there something distinctive about Australian political leadership? Do Australian political leaders employ distinctive strategies? Does the political economy support some types of leadership and not others? If we pursue the focus on the policy transformation, a further set of questions is suggested: have Australian leaders been more successful than leaders in other countries in responding to globalisation through policy and institutional reform? If so, why has this been the case? What is it about Australian political leadership that has led to Australia's improved international ranking on measures of competitiveness, real per capita income, and even freedom?

Political leadership has obviously been at the centre of these changes, and the identification of the main elements of 'the Australian model' that has produced this change becomes a research focus. What have been the features of the political system and culture that have contributed to Australian leaders' innovative capacity? Equally significant in a comparative framework, while Australia has been very successful in pursuing a reform agenda to change the relationship between government and the marketplace, it has not been alone. Indeed, key elements of the program have been copied or adapted from leaders in other countries, and urged on Australia by policy leaders from elsewhere. It is clear that Australian political leaders are a sub-group of a wider category of Western 
political leaders (or is it Anglo-sphere leaders?) and that the Australian case is but one example of a wider shift in Western policy.

\section{Leadership credos: engines of policy change}

Why did this policy revolution occur? Indeed, it is still continuing. What is the most fruitful starting point to try to unravel the intertwined causes of the change? Let us now step back from the big picture and turn the focus to the leaders themselves. If these policy changes have transcended political parties, what is it that has provided the linkage between our political leaders that gives us the most explanatory traction?

I suggest that the most useful starting point is not the personalities of our leaders nor their rhetoric, nor the advisory structures with which they have surrounded themselves, nor the pattern of lobby group pressures they have faced, nor the inexorable challenges of the international economy, but what our political leaders have believed, and what their purposes and values have been: their credos. Certainly they have responded to circumstances, but circumstances only create the opportunity for action. After several decades of involvement as a practitioner I still believe that the most powerful factor in political life is ideas, and I suggest that it is the way in which ideas have been mobilised that should be our starting point. What these ideas are; where they have come from; and more especially how they have been understood by, and mobilised by, political leaders is a central part of the story.

I offer four propositions:

1. The policy dynamism of Australian political leadership in recent decades is a consequence of leaders with developed political credos, committed to policy reform.

2. The driving ideas of this policy program have been largely derived from Australia's unusually homogenous, individualistic, egalitarian and rational democratic culture, mediated in various ways through the requirements of leading one of the major political parties.

3. In developing their policy programs these leaders have been able to draw on a substantial growth in the policy capacity of government arising from expanded knowledge of policy impacts and improved issue analysis. It is this feature that largely explains the major change in policy direction from earlier decades.

4. In implementing policy change Australian leaders have been able to draw upon executive authority of broad scope, including the authority to reorganise the central government apparatus to achieve improved strategic capacity and flexibility in implementation.

The value of the concept of the leadership credo is that it puts the focus on the explicit and formulated ideas of political leaders as they face the choices that 
will lead to policy action. It is a key to understanding the meaning leaders give to the circumstances in which they find themselves, and their efforts to reconstruct these circumstances. It is the leader's credo that will be a key factor in determining whether an opportunity or pressure created by circumstances leads to a particular course of action. As someone who, as a practitioner, has worked with a number of our political leaders in the development and statement of their political credos and who, as a minister, was aware of the ideas driving my own efforts at policy innovation, I am conscious of the significance of these idea sets to the decisions leaders make.

A credo comprises a set of values and beliefs about what is important; what governments can and should do; and how they can be most effective. Over the last 35 years Australian political leaders have worked hard to establish policy agendas; and defining for voters the reality with which they claim politics must deal. Whitlam's mixed offering of big government egalitarianism and liberal tariff reform; Fraser's critique of big government and his social liberalism; Hawke's promotion of consensus; Keating's championing of competition; reconciliation and republicanism; and Howard's explicit avowal of a policy package based on social conservatism and economic liberalism - none of these were 'inevitable' agendas, all were expressions of the leadership credo of the Prime Minister of the day. All were contingent, in the sense that other leaders would probably have pursued other purposes and policies. Their contingent character is emphasised by the fact that we have clear examples of conflicts between political leaders and their principal official advisers (for example, Whitlam and Fraser with Treasury).

In the development of their political credos, Australian political leaders over this period were both 'sellers' and 'purchasers' of ideas. Whitlam's policy program developed over a number of years but, as Prime Minister, he established a policy 'think tank' - the Priorities Review Staff - and actively sought and adopted ideas on economic reform such as tariff reduction. Fraser's speeches over many years reveal a deeply thoughtful approach, drawing on liberal political thinkers he had first met as an undergraduate at Oxford. In office, Fraser assiduously recruited policy thinkers and experts to his political office. Hawke, a former Rhodes Scholar, brought a sharp intellect to a prime ministership that actively sought ideas and political compromise through summits of national business, union and other leaders. Keating's biographer described the ethos of a leadership and advisory structure in which virtue was to be 'at once economically sound and politically clever' (Watson 2002: 89). Howard had worked at ideas for 'future directions' over many years, even if, as his recent biographers suggest, he had no deep interest in political philosophy (Errington and van Onselen 2007: 216). Nevertheless he surrounded himself with the most developed strategic, policy and political staff of any of these leaders, and was comfortable characterising himself along the liberal-conservative dimensions. 
The recognition of the importance of credos is to some extent an antidote to easy cynicism about politics, because it points to the fact that our leaders have deeper purposes and beliefs, and that there is a linkage between these purposes and beliefs and those of the people they claim to represent, and to whom they are accountable.

Leaders, as we know, are not free (if they seek support) simply to advocate whatever public philosophy randomly takes their fancy. They are constrained by the cultural context in which they appeal for support, by the intellectual world of ideas, and by the institutional setting within which they will seek to lead. Their party's policy traditions influence the direction of innovation. How Australians think about their country becomes a constraint and an opportunity. The constraining influence of popular values on leadership credos is a key mechanism by which the values of the Australian people are translated into political action.

\section{Beyond leaders: culture and policy continuity}

Given the differences in political party, personality, background and style of top Australian political leaders during the period of the policy revolution, the continuities over the period require explanation. Circumstances that pushed/encouraged leaders to act are not difficult to find. The Australian policy revolution occurred in an international historical context: the post-World War II world, where much had been learnt about the dangers of protectionism and of the decline of trade for both prosperity and peace, and in which post-war institutions were overseeing an accelerating economic globalisation. It was a context in which the policy survivals of pre-war and war time economic planning in Europe in the pursuit of growth and social justice were increasingly being seen to fail. Australia was experiencing a relative decline in its standard of living and an eroding competitiveness in global markets. The attempt to understand and learn from these failures through policy analysis - located in Australia in the universities, in the central departments of government (Treasury, Finance and Prime Minister and Cabinet), in the central bank and in advisory authorities such as the Industries Assistance Commission - was gathering pace.

But why did Australian leaders come to share a particular set of policy goals and objectives and even policy solutions in response to this situation? In a largely shared context, political leaders in Europe and elsewhere came to different conclusions. In looking for an explanation of the commonalities among the credos of political leaders in Australia, I offer the following proposition. Unlike Europe, the United States or Canada, Australia has a homogenous culture in which two ideas have a dominating role in our political life, and indeed our academic evaluations of politics: democracy and rationality. Australian political leaders argue and debate with each other so strongly - at times bitterly - that it is easy 
to overlook the very large area of agreement between them on the guiding values of policy.

Democratic values are the most powerful drivers and motivators in Australian politics and these values transcend party political differences. The political core of the democratic idea is 'government with the consent of the governed'. A foundation concept, since at least the eighteenth century, has been the idea of the equality of all people, including the equal entitlement of every person to be heard and to pursue their individual values in life. This revolutionary idea has been at work now for over two centuries in our political systems. Policies as disparate as tax neutrality, free market entry, gender equality, educational opportunity, non-discriminatory immigration and accountability of our political leaders, all find justification in the democratic idea. In Democracy in America, Alexis de Tocqueville wrote about the inexorable march of the democratic idea through societal institutions (de Tocqueville 1991: 5-6; see also Rae 1981; Kemp 1987); and we are living in an era when the process is as evident as ever.

Again, the idea of rationality means that action should be justifiable as a rational means of pursuing an objective. Commonsense understandings of the world can be extended by professional experts who attempt to understand more deeply how human beings and human society function and, therefore, how certain ends can be best achieved (for a fascinating analysis of different rationalities see Diesing 1962)

These two concepts - democracy and rationality - link the credos of Whitlam, Fraser, Hawke, Keating, Howard and now Rudd. While there are many differences to which one might point between the public philosophies of these leaders, the continuities are obvious in relation to key aspects of economic reform, gender and racial equality, education, immigration policy and the use of policy analysis, to name but a few.

How can a policy revolution be explained, even in part, by cultural elements which have been around for a long time? The basic answer is again de Tocqueville's: the democratic idea is inherently revolutionary because the search for institutions and policies that will best acknowledge human equality still continues. Australia's rationalist democratic culture sets objectives and points to methods to achieve them. Australian leaders on all sides of politics are deeply imbued with the democratic project. The intensifying process of study, research and learning from experience ensures that it maintains momentum. As a result, the recent policy revolution is only the latest in a series of such phenomena.

Australia has known policy revolutions before. At least two stand out: the initial policy settings of the newly established representative colonial governments in the mid to late nineteenth century and the post-Federation protectionist settlement. The policy revolution of the last three and a half decades is at least 
the third Australia has experienced since the transportation era. In each era circumstances have produced a different policy expression of democratic values.

What is it that has given democratic ideas their particular policy form in the current period? The current Australian policy revolution reflects deep learning about the consequences of different policy frameworks, especially learning about what governments can and cannot do effectively. The failures of protectionism (in Australia and elsewhere) and of government monopolies (in Australia) and central planning (elsewhere) to meet individuals' values revived interest in market-based approaches that can better accommodate diverse wants. The policy analysis that expresses this learning has become a preoccupation of leaders and has led to the establishment of many public agencies and private consultancies. The key central departments - Treasury, Finance and Prime Minister and Cabinet - have played a key role in bringing this policy analysis to the political leadership. The increase in policy analysis has, in turn, led to a weakening of the effectiveness of special interest lobbying and empowered the wider public demand for non-discriminatory policies in all walks of life.

In 1929, Keith Hancock pointed out that Australians were using the collective power of the state in the pursuit of their individual values. He presciently observed:

These policies ... yield diminishing returns, until at last they may become a positive danger to the national purpose that has called them into existence. We have already seen that the increased costs of Protection are endangering the essential purpose of Protection. We shall observe the same tendencies at work in Australian State Socialism (Hancock [1929]1961: 106).

In the 1970s, Australians began to realise, with assistance from a growing army of policy analysts, that important public interests were being sacrificed by the way in which they were trying to achieve their values, especially interests in the economic efficiency and industry competitiveness required to underpin economic growth.

\section{Political parties and policy differences}

Given the level of agreement on the content of the policy revolution, what then have our leaders been debating with each other about? What are the differences in their political credos and what is the significance of these differences? Some of the differences have undoubtedly been rhetorical, prompted by the requirement in election campaigns to highlight real or perceived weaknesses in the other side. Keating's crusade against the horrors of the consumption tax in 1993 falls into this category. At the other extreme some have been, in part, genuine differences in principle or differences that arise from the way in which 
political parties organise values and impose additional constraints on leaders beyond those arising from voters themselves.

Liberal leaders, for example, have been constrained by their party's traditional commitment to the federal system. Fraser, indeed, sacrificed votes in the 1983 election in part because of his commitment to the Federal system despite the Dams Case decision. Howard later sought to move these boundaries in a centralist direction. Again, tariff reform was more straightforward for Whitlam than for a Liberal Party for which protected manufacturing interests were more influential. Conversely, Labor leaders have been constrained by their party's organisational links to the trade union movement and even the economic liberalism of Paul Keating was modified by the corporatism of the Hawke approach. Because of these constraints on Labor, Liberals have pressed further on labour market reform over the years. The effect of the debate between the parties has been to explore and clarify where the strength of the argument lies, and what the relative power of interests will permit.

Have the constraints imposed by the institutionalised values and interests of political party organisations weakened over the years? Labor leaders for many decades have been freer in their policy-making capacity than their party's formal rules might suggest. The constitutional authority granted prime ministers seems largely to have outweighed contradictory party rules. Liberal leaders have always been formally accorded policy autonomy by the rules of the party. In practice therefore, there seems little to differentiate the parties on this dimension. Nevertheless, the constraint imposed on leaders by their need to maintain unity in the party, and to acknowledge the strength of its constituent interests remains even for policy-empowered leaders. The changing social character of the parties' bases means that the nature of these constraints has evolved over time, but the dependence of leaders on the party organisation and on their voting bases means that the constraints continue.

Australian parties seek to embrace large proportions of the electorate and, therefore have incentives to avoid narrow ideological positions. Within the parties, however, ideologies and philosophies are continually debated. Leaders have strong incentives to become proficient in handling the ideas that power the intra-party debates and, hence, to develop their political credos. A common interpretation of the current policy revolution is that it is a victory of liberal over socialist or individualist over collectivist ideas. Certainly a central feature is the search by governments for solutions to problems which allow individual people greater choice and scope in expressing their values.

Divergent philosophical policy frameworks are important for a number of reasons. One is that they provide terms and concepts for leaders. Second, they enable leaders to orient themselves in the historic debates and to take advantage of learning about the functioning of society as the behavioural, social and physical 
sciences develop and elaborate concepts and knowledge in these debates. Political parties provide forums and arenas within which these debates are often crystallised. It is in part through linkages to these debates that researchers and theorists come to impact on the credos of leaders in a changing society. An awareness of these linkages in particular requires us to recognise that the competition between public leaders is, in significant part, a competition of ideas which is not adequately embraced by treating ideas just through their expression as rhetorical devices.

How do the 'grand debates' between liberalism and socialism, individualism and collectivism, over the role of government, and the linkage between human society and the environment relate to the credos of Australian political leaders? The Labor Party has provided the main institutional basis for romantic ideas conflating government and community, and for socialist concepts of government control over the means of production, distribution and exchange. The failure of central planning and the collapse of the socialist states of Eastern Europe had a profound effect on the internal Labor debate and weakened the constraints on leaders from pursuing more market oriented policies. The decisive policy defeat of the socialist Left began under Whitlam, accelerated under Hawke and Keating and has become almost irrelevant under Rudd. A major constraint on Labor leaders thus disappeared.

Over the last century we have been through an era of upheaval in political ideologies and behavioural studies. Our age has been one in which there has been a great contest of ideas over the extent to which policy should and can acknowledge the diversity of individual people, their values and ambitions and be directed to their empowerment, and the extent to which policy should be directed to advancing collective agendas based on nation, class, race, religion and gender. Debates around these ideas between competing public leaders constitute crucial continuities in our political life.

\section{Do all political leaders have credos?}

It has been important in Australian politics for leaders to articulate a credo. The nature of Australian political parties has encouraged a level of expertise in the handling of ideas and offering incentives to find those that will maintain the unity of their party while seeking the middle ground in the wider electorate. To the extent that leaders have been unable, or fail, to do so, their leadership is weakened. The credo relates key values and purposes to preferred outcomes and, therefore, gives both guidance and confidence to leaders as they attempt to deal with the ever-changing complexity of the issues with which time and situation confront them. Howard was a classic case of a leader who shifted decisions to one side of the line or the other depending on the exigencies and demands of the case, but who closely consulted the compass of his credo and sailed as close to the compass line as the prevailing wind permitted. 
For followers, the existence of a leadership credo makes the leader more understandable and predictable, and thus helps to remove one of the threatening uncertainties of leadership - what will the leader do next? Where is the leader taking us? To the extent that there is a match between the values and beliefs of the leader and the followers, the bond in the relationship is strengthened. Indeed, the credo becomes an important element in the establishment of the leader's authority and, beyond authority, persuasive capacity (Lindblom 1977; Kemp 1988; Heifetz 1998). For the academic such credos enable public leadership to be set in a broader intellectual context. For the practitioner, they can provide that important quality of 'standing for something' or 'vision'.

Credos vary along the dimensions of individual belief systems and some have more policy relevance than others. Some are elaborate and broad in scope, others are narrow, some seem to be little more than statements of lobby group sub-culture, while others approach fully fledged political philosophies. Some are flexible, some are rigid. Perhaps we can talk of 'weak' credos and 'strong' credos, but we need a more sophisticated set of descriptive concepts. Peacock, Crean and Beazley seemingly had weak policy credos and lost their leadership largely as a result. Hewson had a strong policy credo but it was narrow and provided an inadequate 'fit' with the values of the electorate. The inability to articulate a convincing credo becomes a problem for a political leader.

\section{Organisational factors: towards prime-ministerial dominance?}

To pursue their policy reform agendas, Australian political leaders have reorganised the institutions of central government to meet their needs: for more sophisticated policy advice, for more flexible means of implementation (and especially for the management of the transition to market approaches), and for more effective political management of the consequences of policies that were often seen as disruptive to existing communities and interests.

A dominant feature of the social and political context of political leadership is continuous change. Leaders, while offering a solution to other people's uncertainties, experience continuing uncertainty themselves, and they are in a good position to do something about it. Leaders are constantly attempting to reduce their own uncertainty in their changing environment. One of the most important ways they do this is by exerting greater control over this environment by improving the skills of their advisers, their co-ordinating capacity, their information flow, and the norms, laws and context governing the behaviour of those causing the most threatening uncertainties. The other major way is by buffering their independence from the pressures upon them by controlling the advisory process and exerting authority. The playing out of these strategies produces continuing evolution in the nature of the institutional environment of 
leadership and in relations between the major institutions of government (Kemp 1987). The last three decades have been especially fruitful in this regard.

Over the last three decades we have a seen a dramatic evolution in the institutions of central government, both on the political advisory side in ministerial staff arrangements and in the Australian Public Service. In some of this I was directly involved, both in the evolution of the Prime Minister's Office as a distinct and significant element at the centre of government, and as minister responsible for negotiating and securing the passage through the Parliament of the Public Service Act 1999.

The democratic idea, in particular, empowered Australian leaders in their reorganisation of government: they saw themselves as leaders with all the legitimacy that comes from having been elected by the people. As such, and within the constraints of the Constitution, they believed they were entitled to have their views prevail. In the course of complex reform, they were entitled to the kind of advice and implementation machinery they felt they needed.

In the first place, they needed a public service expert enough and flexible enough to address the policy demands on it in a way that could deal with the full complexity of the issues. Secondly, they needed political staff who could assist them in their leadership tasks of managing change to obtain the support of the party they led, of the key lobby groups, of the major regions of the country, and of the electorate as a whole.

The dominant issue in relation to ministerial staff was to recognise in the institutional structure that the interests of the political leadership and the public service were not identical, and that there were aspects of political leadership that the public service was not in a position to support. These related to such matters as the setting of priorities, the establishment and communication of the values underpinning policy development, the management of relations with political institutions such as political parties and interest groups and advice on leadership strategies. The theory of the Westminster system had always acknowledged that the public service advised and implemented, but it was the political leader who made decisions. The difficulty was: who would advise the minister on the political aspects of the decisions he was bound to make?

These considerations led Fraser to establish in 1981 a significantly upgraded political staff, of which I was the foundation Director, and an office structure which was largely continued (and further developed) by successive Labor and Coalition governments. As a minister after 1996 I experienced the remarkable capacity to co-ordinate the Ministry which the Prime Ministers Office (PMO) had achieved by that time - a capacity which had not existed twenty years before. Regular discussions were held by the PMO with the staff of ministers and with ministers themselves, within the framework of charter letters in which the Prime Minister set out his annual expectations of ministers in terms of policy 
priorities. Indeed, by the time of the Howard government, the structures designed to assist the Prime Minister in his leadership role within the government had expanded enormously, embracing not only the PMO but the Cabinet Office (headed up by a political appointee who had become Secretary to cabinet) and a prime minister's department which paralleled the co-ordination role of the PMO within the public service.

The Public Service Act 1999 was aimed at greatly increasing the flexibility of leaders in the APS to manage their departments. Senior officers of the service, especially Peter Shergold, later Secretary of the Department of the Prime Minister and Cabinet, led the reforms within the service and with ministers. The greater flexibility assisted in the development of a growing variety of intra- and interdepartmental arrangements as the 'whole of government' approach gathered momentum to better deal with complex problems in areas such as the environment and education.

What are we to learn from this institutional evolution at the centre of Australian government? There is little doubt it led to a strengthening of the dominance of the political leadership in the system of government. This is particularly true of the prime ministership, but it also true of ministers as well within their portfolio areas. It represents, therefore, a lessening of the influence on certain kinds of decisions of the public service. On the other side, however, organisational reform has also produced a level of flexibility in the APS that has empowered it to respond more effectively to policy challenges. The task force on energy policy in 2003-2004 is an example of an innovative approach in which public servants and ministers discussed policy around the cabinet table in a way that would have been unheard of two decades ago.

\section{Conclusion}

The policy revolution of recent decades in Australia is not without parallels in other countries, but the Australian example has had a remarkable coherence and continuity from government to government over three and a half decades, despite some partisan differences.

While globalisation provided the context, the effective policy response by Australian political leaders can be linked to several features of the Australian political system. Australian political leadership is exercised in a notably homogenous democratic and rationalist culture to which both major parties responded with policies emphasising equal access to opportunities for the achievement of individual values. The Australian political system confers broad authority on its leaders to reorganise the arrangements for policy advice and implementation as required. The major political parties, operating in an electoral system that encourages competition for the middle ground, produced leaders with developed policy credos that expressed the shared values of the democratic 
culture, together with a rational approach to policy outcomes that facilitated sophisticated policy analysis and advice from the public service and policy agencies.

\section{References}

de Tocqueville, A., 1991, Democracy in America, (ed. J. P. Mayer, M. Lerner; trans. G. Lawrence), Norwalk, Conn.: Harper Collins, Easton Press.

Diesing, P., 1962, Reason in Society: Five Types of Decisions and their Social Conditions, Westport, Conn.: Greenwood Press.

Errington, W., and P. van Onselen, 2007, John Winston Howard: The Biography, Melbourne University Press.

Hancock, W. K., 1961, Australia, Brisbane, Jacaranda.

Heifetz, R. A., 1998, Leadership Without Easy Answers, Cambridge, Mass.: Belknap Press.

Kemp, D. A., 1973, 'A leader and a Philosophy,' in H. Mayer, Labor to Power: Australia's 1972 Election, Angus \& Robertson, pp. 48-59.

Kemp, D. A., 1988, Foundations for Australian Political Analysis: Politics and Authority, Oxford University Press.

Lindblom, C. E., 1977, Politics and Markets: The World's Political-Economic Systems, New York: Basic Books.

Moore, M. H., 1995, Creating Public Value: Strategic Management in Government, Cambridge, Mass.: Harvard University Press.

Rae, D., 1981, Equalities, Cambridge, Mass.: Harvard University Press:

't Hart, P., and J. Uhr, 2008, 'Understanding Public Leadership in Australia: An Introduction'. Chapter 1, this volume.

Watson, D., 2002, Recollections of a Bleeding Heart: A Portrait of Paul Keating $P M$, Sydney: Knopf. 